\title{
La primera recepción española de la epistemología histórica francesa: Gaston Bachelard (1940-1959) ${ }^{*}$
}

(The First Spanish Reception of the

French Historical Epistemology: Gaston Bachelard [1940-1959])

Francisco VÁZQUEZ GARCíA

Recibido: 30.10.2011

Versión final: 22.01.2012

BIBLID [0495-4548 (2013) 28: 77; pp. 303-327]

RESUMEN: La primera recepción española de la obra epistemológica de Gaston Bachelard tuvo lugar en las décadas de 1940 y 1950. José Pemartín y especialmente Carlos París y Roberto Saumells fueron los filósofos españoles más relevantes que leyeron y utilizaron los escritos históricos y epistemológicos de Bachelard. Estos fueron utilizados para respaldar un realismo ontológico más sofisticado pero no incompatible con el realismo escolástico que prevalecía en la filosofía académica española de esa época. En este artículo exploramos el contexto de esta recepción desde una perspectiva sociofilosófica.

Palabras clave: Bachelard; recepción; filosofía española; franquismo.

ABSTRACT: The first Spanish reception of Gaston Bachelard's epistemological work took place in the 1940s and 1950s decades. José Pemartín and particularly Carlos París and Roberto Saumells were the most important Spanish philosophers who read and made use of the historical and epistemological writings of Bachelard. These were used in order to support an ontological realism more sophisticated but not incompatible with the scholastic realism prevailing in the Spanish academic philosophy of the time. We explore the context of this reception from a sociophilosophical scope.

Keywords: Bachelard; reception; Spanish philosophy; Francoism.

\section{Introducción: ¿una tradición interrumpida?}

Cuando se habla de la tradición francesa de epistemología histórica, el primer nombre que viene a la cabeza es el de Gaston Bachelard (Brenner 2003, 2), bien como eje de la tríada formada por Cavaillès, Bachelard y Canguilhem - una marca consagrada por los discípulos de Althusser desde los años setenta (Fichant y Pécheux 1969; Lecourt 1972; Fichant 1973; Balibar 1978), bien como momento de fractura con la herencia espiritualista recogida por Bergson (Worms 2009, 339-354). Suele olvidarse entonces que ese estilo de reflexión epistemológica sobre la actualidad científica, proclive a recurrir a la historia antes que a la lógica, tiene en Francia raíces profundas. Se trata de una larga estela que, partiendo de Condorcet y pasando por Comte, atraviesa la escuela convencionalista (Duhem, Milhaud, Poincaré, Le Roy), el continuismo histórico de

* Este trabajo se ha realizado gracias a la financiación de la Dirección General del Ministerio de Ciencia e Innovación, dentro del proyecto "Vigilancia de fronteras, colaboración crítica y reconversión: un estudio comparado de la relación de la filosofía con las ciencias sociales en España y Francia (19401990)", referencia FF12010-15196 (subprograma FISO). Agradezco a David Teira y a los revisores anónimos de THEORIA, su ayuda para mejorar este texto. 
Brunchsvicg, Meyerson y Rey, hasta llegar a la mencionada tríada—incluido Koyré-y aún más allá, alcanzando a las obras de Michel Foucault y Michel Serres.

La continuidad de esta tradición empeñada en articular la epistemología a partir de la historia de las ciencias, y que Poincaré caracterizaba como "racionalismo francés" (Castelli Gattinara 1998, 57), contrasta con la accidentada trayectoria española en el terreno de la epistemología de la Física y de las Matemáticas.

En el caso español hay que esperar a las décadas de 1920 y 1930 para encontrar una reflexión sobre estos saberes emancipada de la añeja polémica ideológica sobre la "ciencia española". La conformación de este ámbito epistemológico fue paralela a la constitución de un campo filosófico profesional y de una Universidad relativamente autónoma respecto a los poderes políticos y eclesiásticos, un proceso que acabó cristalizando en la constitución de las escuelas de Madrid y de Barcelona.

Esta reflexión epistémica sobre la ciencia en curso, esto es, principalmente sobre el alcance de la crisis de la física clásica, las teorías de la relatividad y la teoría de los quanta, la protagonizaron científicos como Blas Cabrera y Rey Pastor (Glick 1986, 18 20, 113-17; Sánchez Ron 1999, 213-23) y filósofos como Ortega, Zubiri y García Bacca (Ronzón 1983, 39; Glick 1986, 196-205). Ortega se interesó especialmente por los problemas de la teoría de la relatividad, ${ }^{1}$ con la que llegó a estar bastante familiarizado, participando activamente en su difusión a través de Revista de Occidente y de la editorial Calpe (Madrid 2005).

El caso de Zubiri y de García Bacca, resulta bastante peculiar. Formados como sacerdotes-enraizados familiarmente en el acendrado catolicismo vasco y navarro, y en una línea afín al neotomismo representado por la Universidad de Lovaina—, su punto de partida lo constituía el intento-definido programáticamente por el padre Domingo Lázaro (Moreno Pestaña 2008, 23)—de conciliar las aportaciones de la ciencia postclásica con los principios fundamentales de la fe católica. Más aún, en vez de contraponer la ciencia y el dogma, se conminaba a los teólogos para que estudiaran las ciencias, con objeto de demostrar que éstas tenían tantas fragilidades como la religión.

Zubiri y García Bacca se aplicaron a la tarea con ahínco. Ambos conocieron de cerca el trabajo realizado en el Instituto de Física Teórica de Munich, donde se había formado buena parte de la generación de físicos teóricos que había revolucionado la disciplina (Corominas y Vicens 2005, 217-37; García Bacca 1982, 4-8; Ayala 2005). Este capital científico, combinado en el caso de Zubiri con importantes recursos de historia de la filosofía, y en el de García Bacca con una sólida formación en lógica simbólica, les permitió trascender los propósitos meramente apologéticos de su motivación inicial, retraduciendo los debates de la revolución física en curso al lenguaje específico de la filosofía. ${ }^{2}$

\footnotetext{
${ }^{1}$ Especialmente en textos como "El sentido histórico de la teoría de Einstein" (1924, incluido como apéndice en El tema de nuestro tiempo) y "Bronca en la Física" (1937).

${ }^{2}$ García Bacca se doctoró en 1935 con una tesis titulada Ensayo sobre la estructura lógico-genética de las ciencias físicas. Zubiri se ocupó de la "nueva física" en la tercera parte de Naturaleza, Historia y Dios, editada en 1944, donde se recuerda que sus reflexiones se remontaban a 1934 (Zubiri 1978, 244, 273).
} 
Esta autonomía y buen nivel alcanzados por la reflexión epistemológica española, se vieron afectadas por el impacto de la Guerra Civil, las depuraciones del medio universitario y la reordenación de los estudios de filosofía dictada por la Administración franquista. En las décadas de 1940 y 1950, toda una pléyade de eclesiásticosespecialmente jesuitas desde Pensamiento y Razón y Fe, y dominicos desde La Ciencia Tomista y Estudios Filosóficos, e intelectuales afines a Falange o al Opus Dei, retomaron la tarea de descifrar el alcance filosófico de las revoluciones experimentadas por la física contemporánea. El discurso epistemológico parecía convertirse en una pobre eufemización de la apologética religiosa o de la propaganda política. Se trataba de mostrar que la crisis del determinismo y de los modelos mecanicistas revalidaba, desde la nueva física, la doctrina teológica del libre arbitrio; de avalar el providencialismo de la cosmología católica sobre la base de la teoría de la relatividad; de manifestar la fragilidad de la verdad científica, otrora soberbia, frente a la teología, o de compatibilizar la mecánica cuántica con la metafísica de la sustancia de inspiración aristotélico-tomista. Desde el polo político se trataba de casar el "metarrelato nacionalcatólico" (Juliá 2004, 287-97) que legitimaba al régimen con el advenimiento de una era espiritual, postcartesiana y antiilustrada, encarnada por la nueva España y simbolizada por la crisis de la física clásica.

A pesar de esta pérdida de autonomía en el discurso epistemológico, la continuidad con la etapa anterior no se desvaneció. García Bacca se exilió mientras que Ortega y Zubiri permanecieron al margen del mundo universitario, pero el primero consiguió conectarse con los jóvenes filósofos del interior a través de sus colaboraciones en THEORIA (Ronzón 1992, 641) y el segundo prosiguió la elaboración sistemática de su filosofía de la razón vital en medio de la incomprensión e incluso de campañas de rechazo (Morán 1998; Zamora Bonilla 2002). El caso de Zubiri es diferente. Sus reflexiones sobre la nueva física, formando parte de Naturaleza, Historia, Dios, se editaron en 1944, pero recogían reflexiones anteriores, editadas respectivamente en Cruq y Raya (Zubiri 1934) y en Escorial (Zubiri 1941). El libro mencionado, como sucederá con los cursos privados impartidos por el filósofo vasco a partir de octubre de 1945 (Corominas y Vicens 2005, 523-40), tendrán bastante resonancia, dando lugar a un grupo de jóvenes intelectuales afines al falangismo y aglutinados por la relación discipular con Zubiri, entre los que destacaron Laín Entralgo, Javier Conde y Gómez Arboleya.

En esta continuidad con la etapa anterior a la Guerra y preservando cierta autonomía para el discurso epistémico sobre la actualidad científica, se inscribe el proyecto de la revista THEORIA, nacida primero como un cuadernillo anexo a la revista Alcalá (Ronzón 1983, 12), publicada en el entorno de los círculos seuístas. La publicación fue respaldada institucionalmente por la sección de Filosofía e Historia de la Ciencia del Instituto Luis Vives, ${ }^{3}$ que se había fundado en 1950 y estaba patrocinada por la Secre-

${ }^{3}$ La mayoría de los estudiosos (Jiménez García 1982, 45-46; Ronzón 1983, 23; Peña 1993, 321-23) la designan como "sección de Filosofía e Historia de la Ciencia", que es el nombre que recibió desde su fundación hasta que se produjo el exilio de Sánchez-Mazas en 1957. Carlos París (2006, 99-100) en sus Memorias lo denomina "Departamento de Epistemología e Historia de la Ciencia", denominación que obtuvo después de este episodio. Agradezco estas precisiones a uno de los informantes anónimos del presente trabajo. 
taría General del Movimiento. A comienzos de la década de 1950, todavía no se había producido la ruptura entre este proyecto, vinculado al grupo de los zubirianos falangistas (Conde, Gómez Arboleya, Laín), y el alentado por el opusdeísta Calvo Serer, nucleado en torno a la revista Arbor, también editada dentro del organigrama del CSIC. La cooperación entre los intelectuales de ambos grupos era frecuente, de ahí la presencia, a fines de los años cuarenta y comienzos de los cincuenta, de jóvenes filósofos de ambos nódulos como colaboradores en las mismas revistas, publicando artículos y reseñas sobre filosofía de la naturaleza, lógica simbólica o epistemología de la física y de las matemáticas. ${ }^{4}$

Un rasgo de continuidad entre el discurso epistemológico propio de esta "unidad generacional" 5 y el representado por Ortega y Zubiri-no tanto en el caso de García Bacca-es la preponderancia de las referencias francesas—o francófonas-sobre las anglosajonas y germánicas. La interpretación orteguiana de las teorías de Einstein se atiene bastante fielmente a los supuestos convencionalistas de Duhem y de Poincaré ${ }^{6}$ - autor ampliamente traducido en Espasa Calpe en los primeros años cuarenta. ${ }^{7}$ Duhem y Poincaré son asimismo referencias fundamentales en las consideraciones de Zubiri sobre la nueva física. ${ }^{8}$

${ }^{4}$ Las pruebas de esta cooperación son indiscutibles. José Luis Pinillos formó parte del equipo de base en la redacción de Arbor (Díaz Hernández 2008, 92) y al mismo tiempo colaboró en la fundación de THEORIA (Ronzón 1983, 11). Sánchez-Mazas (con numerosas reseñas en la primera mitad de la década de los 50) y Carlos París (con varios artículos) colaboraron en Arbor. Cuatro hombres muy vinculados a Arbor (Raimundo Pániker, Millán Puelles, Pérez Ballestar y José Luis Pinillos) colaboraron con artículos en THEORIA (Ronzón 1992, 639-42). Una obra de Millán Puelles fue reseñada en esta misma revista y otra de este mismo autor fue recensionada por Carlos París en la Revista de Filosofía. Por otro lado, Carlos París publicó su tesis doctoral, Física y Filosofía (1952a) en la colección de publicaciones del Departamento de Filosofía de la Cultura, dirigida por Rafael Calvo Serer. A esta colaboraciónentre el grupo de Arbor y los falangistas zubirianos-alude (Díaz Hernández 2008, 205-206), aunque la sitúa a finales de la década de los 40 . Es evidente que se prolonga más allá de esta fecha.

${ }^{5}$ Sobre la distinción, originariamente establecida por Karl Mannheim, entre "localización generacional", "unidad generacional” y "complejo generacional", véase (Mannheim 1993)

${ }^{6}$ Con independencia de que la perspectiva de Ortega sobre la física sea o no propiamente "gnoseológica"-tal como niega (Ronzón 1983, 40), se ha argumentado desde hace tiempo (París, 1957a, 98), (Madrid 2005), su afinidad con los planteamientos convencionalistas de estos epistemólogos franceses.

${ }^{7}$ En 1943 se vertió al castellano en la casa argentina de Espasa Calpe, La ciencia y la bipótesis, que fue seguida por Ciencia y método (1944) y El valor de la ciencia (1946). Este interés no era nuevo; Poincaré ya había sido traducido al castellano en España. En 1906 vio la luz El valor de la Ciencia; en 1907 Ciencia e Hipótesis y en 1909 Ciencia y Método. Agradezco esta información a uno de los evaluadores del presente trabajo.

${ }^{8}$ En el capítulo que Naturaleza, Historia, Dios dedica a la reflexión sobre la nueva física, estos dos autores—junto a Mach—son los únicos epistemólogos citados, el resto son físicos teóricos, (Zubiri, 1978, 277). González Fernández $(1994,79)$ alude a la importancia de estos autores ya en la tesis doctoral de Zubiri, defendida en 1921 y publicada en 1923. Además, Zubiri considera que fueron "voces aisladas" y "desoídas" que advirtieron con tino—y frente a los propios físicos—la incompatibilidad de la nueva física con el realismo cosista. 
Esta pregnancia de la tradición francesa se mantiene asimismo en el grupo de THEORIA. Ciertamente las consideraciones epistemológicas de Sánchez-Mazas se sustentan más en el análisis lógico que en la historia de las ciencias, pero la referencia primera de su interés por Leibniz y por la lógica procedió de Couturat, que le condujo también a Russell, y no al revés (De Lorenzo 2002, 11-14). ${ }^{9}$ Gustavo Bueno, vinculado también al proyecto de THEORIA y a la célebre tertulia de la cervecería Gambrinus, también era buen conocedor de esta tradición francesa de epistemología histórica (Meyerson, Brunchsvicg, Bachelard) (Bueno 1955, 245, 260-261, 270). En el caso de Carlos París-cuyo primer libro, anterior a su tesis doctoral, es un alegato contra el positivismo lógico (París 1951-52)—esta filiación francesa es indiscutible.

Pues bien, en este contexto se produce la primera recepción española de Bachelard. Este hecho ha permanecido prácticamente en el olvido. El triunfo de una filosofía del lenguaje y de la ciencia de matriz empírico-analítica, evidente en grupos filosóficos como los nucleados por Manuel Garrido, por los herederos de Aranguren (Muguerza, Hierro Pescador), por Manuel Sacristán o por el propio Sánchez-Mazas en la segunda etapa de THEORIA, ${ }^{10}$ ha eclipsado por completo esta presencia francesa, llevando incluso a interpretar retrospectivamente el grupo de THEORIA como una suerte de islote analítico en medio de un océano escolástico. ${ }^{11}$ A esto se unió el redescubrimiento de Bachelard y de la epistemología francesa en el curso de los años 70, a la sombra de la recepción fulgurante y relativamente efímera de la obra de Althusser. ${ }^{12}$

${ }^{9}$ En Sánchez-Mazas, como sucede en Drudis Baldrich—otro importante colaborador de THEORIA, las referencias a Russell, Wittgenstein, el Círculo de Viena y la escuela de Berlín resultan predominantes, lo que resulta coherente con las preferencias de estos autores por la lógica antes que por la historia de las ciencias. Sin embargo Sánchez-Mazas concede mucha importancia a la epistemología francófona, comentando elogiosamente el llamado "movimiento dialéctico", un grupo radicado en Zurich, editor de la revista Dialectica y en el que se engloba a epistemólogos como Gonseth, Destouches y el mismo Bachelard (Sánchez-Mazas 1952, 71). Este agrupamiento, un tanto peculiar como se verá más adelante, es fundamental en la obra epistemológica de Carlos París. También resulta relevante el hecho de que Rey Pastor-primer director de la sección de Filosofía e Historia de la Ciencia del CSIC, que regresó a España desde Argentina-estuviera muy vinculado con el Grupo de Historia y de Filosofía de la Ciencia de la Sociedad Argentina de Filosofía, nucleado en torno al profesor Raymundo Pardo, y donde las referencias de la epistemología francesa (Bachelard incluido) resultaban cruciales (Álvarez de Linera 1953, 162-63). Por otra parte, el número de obras en francés, recensionadas en THEORIA, resulta bastante considerable: 16 obras en castellano, 12 en inglés, 9 en francés y 5 en alemán.

${ }^{10}$ Sobre estos grupos, (Vázquez García 2009).

${ }^{11}$ Véase el excelente estado de la cuestión sobre el grupo de THEORIA expuesto por (Ronzón 1983). El mismo Sánchez-Mazas, en el monográfico de THEORIA publicado con motivo de los cuarenta años de la revista, efectuó esta lectura retrospectiva, sesgadamente "analítica": "merced al esfuerzo de aquellos jóvenes españoles, la lógica matemática, las ideas de Russell y el Wittgenstein del Tractatus brillaron con súbito destello en el madrileño ambiente de oscuridad cultural" (Sánchez-Mazas 1992, 6).

12 Aparte de esta recepción posterior vinculada al althusserianismo, hay que mencionar, en el terreno de la renovación pedagógica de las matemáticas, la importancia de Bachelard-principalmente a través de la obra de Brosseau — en la escuela de Granada, liderada por el profesor Luis Rico y por su esposa. Agradezco esta información a uno de los evaluadores del presente trabajo. 


\section{Bachelard y la ontología politica del nacionalcatolicismo: José Pemartín}

En la circulación internacional de los bienes intelectuales, toda importación de una obra o de un autor implica su descontextualización del campo original y de las luchas simbólicas correspondientes y su recontextualización en el propio campo, integrando los planteamientos importados en un marco de combates teóricos y de estrategias argumentativas completamente extrañas a las del territorio original. En este sentido, las diferencias entre recepción y creación, entre consumo y producción, quedan fuertemente atenuadas (Pinto 2009b, 9-15). Estudiar la recepción de una obra filosófica implica por ello dar cuenta de las estrategias de lectura-necesariamente selectivas y sesgadas-que fueron utilizadas, reconstruyendo al efecto las trayectorias de los importadores para dilucidar las disposiciones que engendraban esas estrategias, así como las diversas aleaciones de capital (académico, político, intelectual) que conformaban esas disposiciones. Esas trayectorias se emplazan dentro de un campo filosófico de destino, marcado por las luchas entre los distintos grupos intelectuales que lo constituían y que pugnaban por conservar o transformar la jerarquía entre los objetos simbólicos que vertebraban ese campo (jerarquía estipulada entre las disciplinas, canon de autores, menú de opciones teóricas disponibles, etc). ${ }^{13}$ Es el caso de la obra epistemológica de Bachelard, trasplantada, desde mediados de los años cuarenta, a un medio filosóficoel español—cuya autonomía respecto al campo político y religioso se encontró considerablemente mermada al hilo de la reestructuración del mundo intelectual y universitario emprendida por las autoridades franquistas. Toda obra filosófica, como señala Pierre Bourdieu a propósito de Heidegger (Bourdieu 1991, 12-17), tiene una condición estrábica; remite por un lado a un horizonte específico, técnico y profesional de problemas filosóficos; por el otro abre la posibilidad de connotaciones y valencias político-ideológicas.

Pues bien, en el caso de las aportaciones epistemológicas de Bachelard, que remiten a estudios muy especializados sobre la historia de los conceptos científicos, esas connotaciones entroncan con los valores de seriedad y rigor propios de la tradición racionalista francesa - como en el caso de su maestro Brunchsvicg (Pinto 2009a, 203) - y con el laicismo y el igualitarismo universalista, disposiciones características de intelectuales franceses de origen provinciano y relativamente modesto como Cavaillès, Bachelard o Canguilhem, verdaderos "oblatos" de la escuela republicana (Bourdieu 1997, 49-50).

En España, sin embargo, las primeras referencias relevantes a la epistemología bachelardiana se encuentran en José Pemartín (1888-1954), uno de los padres intelectuales del nacionalcatolicismo español (Quiroga Fernández de Soto 2007). Nacido en una familia de bodegueros y terratenientes jerezanos, su formación transcurrió en París durante casi toda la primera década del siglo XX, donde se tituló como ingeniero meta-

\footnotetext{
${ }^{13}$ Sobre las estructuras del campo filosófico español en la época mencionada, incluido el mapa de las instituciones, revistas, redes y grupos filosóficos en liza, (Vázquez García 2009, 83-86).
} 
lúrgico y tuvo ocasión de asistir, en 1904, a los cursos impartidos por Bergson en el Collège de France. ${ }^{14}$

Durante la Dictadura primorriverista desempeñó diversos cargos políticos y se convirtió en uno de los intelectuales orgánicos más importantes de este régimen, formando parte del comité de la Unión Patriótica, el partido fundado por Primo. Conferenciante y ensayista político, formó parte de diversas iniciativas de la derecha española, como la fundación de la Unión Monárquica Nacional en 1930 y de Renovación Española en los años de la República; asimismo fue un asiduo colaborador, desde sus inicios, con la publicación derechista, Acción Española. Una constante de su trayectoria la constituye el intento de aunar la tradición católico-integrista española (desde Donoso Cortés, Vázquez de Mella y Menéndez Pelayo) con el elemento modernizador del fascismo. Amigo personal de José Antonio, desempeñó, tras el inicio de la Guerra Civil y en el Gobierno de Burgos, los cargos de Jefe del Servicio nacional de Enseñanza Superior y Media y miembro del Consejo Nacional de FET y de las JONS. Publicó también algunos textos de pedagogía, sosteniendo que de la Institución Libre de Enseñanza "no ha de quedar piedra sobre piedra" (Rodríguez Puértolas 2008, 462).

Dotado de una formación técnica muy exigente, Pemartín estuvo desde muy joven interesado por la filosofía y por los desarrollos revolucionarios de la física contemporánea. En 1933 publicó un artículo en Acción Española, donde arremetía contra la interpretación orteguiana de la teoría de la relatividad-Ortega subrayaba el antirracionalismo y anticartesianismo einsteinianos- señalando en cambio el entronque de Einstein con el pensamiento de Descartes (Glick 1986, 199-200).

Por iniciativa de Accción Española, Pemartín tenía previsto impartir en el verano de 1936 un curso abierto dirigido a estudiantes universitarios de Madrid. Recogidas en el volumen titulado Introducción a la filosofía de lo temporal. Doce lecciones sobre espacio-tiempocausalidad (1937), estas conferencias-que debido a las circunstancias no pudieron finalmente pronunciarse-muestran el entrelazamiento del discurso filosófico de Pemartín sobre la ciencia con elementos propios del fascismo europeo del momento así como con el metarrelato de la historia de España de hondas raíces en el conservadurismo católico español. Siguiendo un tópico ya recogido por Ortega (Moreno Pestaña 2008, 31-33) y reconfigurándolo a partir de Heidegger, el vitalismo occidental (Nietzsche, Bergson) y la fenomenolgía (Pemartín 1941, 179), contrapone la primacía de lo cualitativo, propia de la existencia auténtica, al imperio de lo cuantitativo característico del pensamiento moderno. Pemartín proyecta estas polaridades conceptuales en su diagnóstico de la nueva física. Contrasta la física de la relatividad, que conduciría a radicalizar la espacialización del Universo, con las aportaciones de la mecánica ondulatoria (De Broglie, Schrodinger, Heisenberg, Dirac), que parecen en cambio rebasar los privilegios de lo espacial y lo material enfatizando la textura temporal del cosmos. De este modo, las contribuciones más recientes de la física anunciarían también la des-

${ }^{14}$ Toda la información sobre la trayectoria de Pemartín está tomada de (Quiroga Fernández de Soto 2007; Rodríguez Puértolas 2008; y Díaz Hernández 2008, 50-51). Asimismo, agradezco a Álvaro Castro, que prepara una monografía sobre Pemartín, las informaciones que me ha proporcionado sobre este personaje. 
composición de la mentalidad científica moderna, caracterizada por el mecanicismo, el materialismo y la geometrización.

En la Introducción a la filosofía de lo temporal, Pemartín no cita aún a Bachelard, pero bosqueja las estrategias argumentativas que le van a permitir utilizarlo en el marco de una ontología política de corte nacionalcatólico. A partir de la década de 1940, Pemartín estuvo muy vinculado al Instituto Luis Vives de Filosofía (CSIC). Durante los años cincuenta fue socio de número de la Sociedad Española de Filosofía (como Miguel Sánchez-Mazas o Aranguren), ligada a este organismo, interviniendo en distintas sesiones científicas de la misma (Ronzón 1983, 21-22) y publicando varios artículos en la Revista de Filosofía, órgano del Instituto Luis Vives, así como en la revista Arbor e incluso en el primer número de THEORIA (Pemartín 1952). Tras la fundación de la sección de Filosofía e Historia de la Ciencia, colaboró también como conferenciante en las sesiones científicas de este departamento, llegando a presidir la que inauguró el curso 1953-54 (Ronzón, 1983: 123).

La primera referencia relevante de Pemartín a la obra de Bachelard se localiza en un artículo publicado en 1944 (Pemartín, 1944). Una vez más, el trasfondo de la argumentación lo constituye el metarrelato nacionalcatólico, evocado esta vez a través de la versión del mismo dada por el padre Ceferino González. Se hace referencia a la hegemonía del "cartesianismo", representando, no sólo un sistema filosófico, sino toda una herencia civilizatoria marcada en lo político por el absolutismo y la revolución; en lo religioso por el descreimiento anticristiano; en lo cultural por la primacía francesa y el espíritu ilustrado. Pemartín quiere mostrar la quiebra de este legado-verdadera encarnación de lo "antiespañol"-en el terreno científico. Para ello busca respaldo en un capítulo de Le Nouvel Esprit Scientifique (1934), donde Bachelard diagnostica el perfil epistemológico de la física contemporánea, calificándolo de "no cartesiano" (Pemartín 1944, 439).

El análisis de Bachelard se presenta con un signo ambivalente. Por una parte contribuye a corroborar magistralmente la disolución de los supuestos cartesianos operada en la física actual. Pero al mismo tiempo, su insistencia en el puro carácter abstracto y matemático de las entidades de la nueva física—donde el simbolismo algebraico no es, como en la mecánica clásica, un instrumento descriptivo sino constitutivo de los fenómenos- lo llevaría a apostar por una suerte de realismo pitagórico-platónico (Pemartín 1944, 451).

Esta estrategia consistente en incluir la epistemología bachelardiana en las huestes del realismo tendrá, ${ }^{15}$ como se verá, un porvenir prolongado. No obstante, Pemartín rechaza ese realismo matemático, que considera una recaída en la "cartesianización a ultranza" (Pemartín 1944, 458). Esta opción reduce el papel de la experiencia a la mera materialización de lo estipulado por los sistemas axiomáticos que conforman la teoría. Por eso contrapone el realismo sustancial de Meyerson, más consonante con la tradición aristotélico-tomista, al realismo pitagórico-platónico de Bachelard.

\footnotetext{
${ }^{15}$ Sobre la problemática inclusión de la epistemología bachelardiana en el realismo y su posible compatibilidad con el "racionalismo aplicado", (Tiles 1984, 42-44, 127-128, 216-217).
} 
El segundo pecado imperdonable de Bachelard consistiría en sugerir una herética subversión de las jerarquías disciplinares. Calificando de "antifilosófico" el intento bachelardiano, Pemartín señala que el filósofo francés pretende, erróneamente, deducir la epistemología a partir de la ciencia experimental, cuando justamente habría que proceder al revés. Las hechuras de las teorías físicas deben derivarse a partir de fundamentos epistemológicos previos que, a su vez, descansan sobre sólidos principios ontológicos y en último término metafísicos (Pemartín 1944, 464). Esta acusación de trastocar el orden de los saberes también tendrá continuación, como más adelante se comprobará.

Bachelard tampoco parece percatarse, según Pemartín, del contraste entre la marginación de la temporalidad entrañada en la formulación einsteiniana de la relatividad y su asunción en la teoría de los quanta. La primera entroncaría con la "extratemporalidad" típica del cartesianismo, mientras que la segunda anunciaría la recuperación del tiempo en el pensamiento actual. Por un juego de analogías salvajes, este contraste se equipara al establecido entre una ética, una política y una sociología abstractas y geométricas, propia de ilustrados, liberales y revolucionarios, contrapuesta a las inspiradas por los vitalismos, historicismos y existencialismos, que exaltan lo temporal. Como cabía esperar, esta vindicación de lo temporal se asimila a la recuperación de la teleología.

Esta última maniobra retórica le permite a Pemartín enlazar de nuevo, al final de su texto, con el gran relato nacionalcatólico. La herencia cartesiana habría conducido a la disyuntiva moderna entre un idealismo abstracto, "sin cuerpo" y un positivismo grosero, "sin alma". La crisis de esta mentalidad, que encarnaría todas las virtualidades de la anti-España, anunciada en física por la recuperación de una temporalidad irrebasable y teleológica, reacia a toda forma de mecanicismo, implicaría al mismo tiempo la restauración de los valores inherentes a la auténtica tradición española. Entre ellos, y en primera fila, la "filosofía perenne", invocada como la referencia que debe fundar ontológicamente el rumbo de la física actual para sacarla definitivamente de una pendiente deshumanizadora propiciada por el lastre cartesiano.

En otras intervenciones posteriores, Pemartín abunda en su interpretación haciendo hincapié en esta retórica acerca de la "deshumanización". En 1946 publicó en la Revista de Filosofía un artículo donde elogiaba la lectura que el filósofo E. A. Milne hacía de las teorías generalizada y restringida de la relatividad (Pemartín 1946). Frente a la presentación einsteiniana, que tiende a sacrificar la temporalidad en una suerte de hiperespacialización del Universo, Milne propone un acercamiento que trata de compatibilizar la teoría de la relatividad con la experiencia temporal del observador real. Se vuelve a citar Le Nouvel Esprit Scientifique presentándolo como un agudo diagnóstico del hipermatematismo propio de la física actual (Pemartín 1946, 483); pero en vez de reconocer esta condición como un valor, al modo bachelardiano, se advierte en ella una pérdida del horizonte temporal, considerado por Pemartín—en la estela de Bergson y de Heidegger- como lo específicamente humano.

En ese esfuerzo para "rehumanizar" la nueva física se inscribe una tercera contribución de Pemartín, también recogida en la Revista de Filosofía (AAVV, 1953). La referencia a Bachelard se reitera: Le Nouvel Esprit Scientifique capta muy bien el "hiperpita- 
gorismo" de la física actual, pero olvida—debido a la desacertada manía de subordinar la filosofía a la ciencia - ponderar sus peligros. Este matematismo extremo lleva a relegar el papel de la experiencia, convertida en mera ilustración de complejas construcciones axiomáticas. ${ }^{16}$ Se rompe así el equilibrio gnoseológico entre teoría y experiencia, en detrimento de la segunda, pero también el "equilibrio antropológico" entre las dimensiones del conocimiento y de lo "sensible-vital". Para corregir esta hipertrofia intelectualista, Pemartín apela a una filosofía de la naturaleza avalada por la "posición antropológica tomista" (AAVV 1953, 153).

\section{Bachelard y el realismo abstractivo: Carlos París}

Carlos París (n. 1925) pertenece a una unidad generacional diferente a la de Pemartín. No forma parte de los que hicieron la Guerra sino de los que empezaron a ocupar posiciones de responsabilidad pública cuando el régimen trataba de salir de la situación de aislamiento propiciada por la derrota de las potencias del Eje, a través de los acuerdos con el Vaticano y con la Administración norteamericana.

Por otra parte, la trayectoria y el perfil de Carlos París difieren mucho de los que presentaba José Pemartín. En la década de los cincuenta, París era ya un filósofo universitario, no un intelectual orgánico como Pemartín; sus cargos se emplazaban en los aledaños del mundo académico, no en la cúpula política del régimen. Hijo de un director de sucursal bancaria próximo a la CEDA, Carlos París fue inscrito como flecha y siendo bachiller perteneció al Frente de Juventudes, pero nunca llegó a militar en la FET de las JONS (Marsal 1979, 206). Director de un Colegio Mayor del SEU en Santiago de Compostela (1954-58) (París 2006, 94-97), estuvo desde su época de estudiante vinculado al Instituto de Cultura Hispánica, a través de su pertenencia a la Asociación Cultural Iberoamericana, dirigida por Laín (París 2006, 71-73). El Instituto, dirigido sucesivamente en esa época por los acenepistas Ruiz-Giménez y Sánchez Bella constituía uno de los grupos intelectuales que, a finales de los años 40, pugnaba, junto al Instituto de Estudios Políticos dirigido por Javier Conde y el grupo Arbor regido por Calvo Serer, por la hegemonía en el campo intelectual. En esa época existía una alianza tácita entre los dos primeros grupos. Carlos París colaboró desde muy pronto en las publicaciones vinculadas al SEU, como fue el caso de Alférez y especialmente de La Hora y Alcalá.

Adjunto en la Facultad de Filosofía de la Universidad Central de Madrid poco después de finalizar la carrera (1946), consiguió el doctorado en 1950, con una tesis dirigida por Yela Utrilla (1893-1950), fallecido en abril de ese mismo año. Este era un falangista ortodoxo y con importantes méritos de guerra que en 1942, con motivo del aniversario de la muerte de Galileo, arremetía contra la interpretación orteguiana del personaje, desmontaba su condición de supuesto "mártir" de la ciencia y resaltaba su papel en el "pensamiento descarriado y sin sentido que arranca del Renacimiento" (Yela Utrilla 1942,117). Un año después del doctorado, Carlos París consiguió la cáte-

${ }^{16}$ Pemartín (AAVV 1953, 157) tiene aquí muy presente la tesis doctoral de Carlos París, Física y filosofía, leída en 1950 y publicada en 1952, aunque obvia por completo el modo en que París incorpora la "dialéctica" bachelardiana para dar cuenta de la relación entre teoría y experiencia 
dra de Fundamentos e Historia de la Filosofía en la Universidad de Santiago. De este modo acumuló, en muy poco tiempo, todos los signos de la excelencia académica.

Esa coyuntura diferente y esa extensa cultura filosófica profesional explican en parte que la reflexión de Carlos París sobre la ciencia, en contraste con la de Pemartín o con la de su director de tesis, ofrezca un tono mucho más técnico y distanciado respecto al discurso puramente ideológico, donde la presencia del metarrelato nacionalcatólico se hace prácticamente invisible. Esto no significa que su amplia obra epistemológica-en la década que nos interesa, entre 1949 y 1958-tenga el perfil de una filosofía de la ciencia plenamente adelantada a su tiempo, como la que habría de hacerse a partir de los años setenta en núcleos como las Universidades de Valencia, Barcelona, Oviedo o Autónoma de Madrid. Lo que Carlos París defiende en los escritos de la mencionada década es una filosofía de la naturaleza, esto es, una ontología y una metafísica coherentes a la vez con la tradición aristotélico-tomista-finalmente renovada a través del diálogo con la obra de Amor Ruibal—y con los datos de la actualidad científica. ${ }^{17}$

En el corpus relativamente extenso, que constituye la obra filosófica de Carlos París entre 1949 y 1958, se advierte el intento de crear una posición propia a partir de un menú de opciones teóricas posibles, en relación con el siguiente problema: ¿cuál es la relación entre ciencia y filosofía y qué pertinencia tiene en ella el discurso metafísico, o más específicamente la filosofía de la naturaleza en tanto que reflexión ontológica sobre el ente material? El siguiente cuadro representa ese espacio de posibles mediante el recurso a las tablas de verdad: ${ }^{18}$

\begin{tabular}{|c|c|c|}
\hline OPCIONES & FILOSOFÍA & CIENCIA \\
\hline Kantismo-Realismo crítico & - & + \\
\hline Convencionalisno & + & - \\
\hline Neopositivismo & - & - \\
\hline Realismo escolástico & + & + \\
\hline
\end{tabular}

El kantismo y su versión más actualizada, el "realismo crítico"—con Nicolai Hartman como figura principal—sostendría que la única metafisica legítima es la que se apoya en una síntesis de los resultados ofrecidos por la ciencia positiva $(+)$, una suerte de

\footnotetext{
${ }^{17}$ Los trabajos sobre esta obra epistemológica de Carlos París, publicados en volúmenes de homenaje editados en los años ochenta y noventa (Mínguez 1987, 1997; Ferraz 1997), no deben ser tomados como un análisis objetivo de sus primeros escritos, sino como elementos de un verdadero ritual de sacralización. París aparece convertido en un "objeto sagrado" durkheimiano, un precursor de la filosofía de la ciencia que habría de cuajar en España veinte o veinticinco años más tarde. El propio Carlos París, en sus Memorias queda presa de esta lectura retrospectiva cuando, por ejemplo, interpreta su interés por Bachelard como una actitud revestida con todas las atribuciones del vanguardismo: "en España di a conocer su pensamiento y dirigí tesis sobre su obra, la cual influiría años después en las posiciones marxistas de Althusser" (París 2006, 115).

${ }^{18}$ Sobre esta técnica de las “tablas de verdad”, (Becker 2002, 259-329).
} 
"metafísica inductiva" (París 1952b, 170) que no traspasa los límites de la experiencia (París 1952a, 322) y que prohíbe a la filosofía toda pretensión de especulación metafísica independiente (-) (París 1952a, 43-4, 55-6).

El convencionalismo (París 1949, 304-6) niega en cambio el alcance ontológico de las teorías científicas (-). Estas consisten en un simbolismo matemático que permite "salvar los fenómenos" sin compromiso con ninguna realidad más allá de éstos. Queda entonces todo el terreno abierto para una ontología del ente material, esto es, una filosofía de la naturaleza de perfil aristotélico-tomista, divorciada de la ciencia positiva y referida a la experiencia cotidiana (+). Algunos escolásticos como Maritain y Renoirte se inclinarían básicamente por esta opción (París 1952a, 68-72; París 1957c, 420).

El neopositivismo, por su parte—expuesto y despachado críticamente por París en su primer libro (París 1951-52)—, supone el rechazo de toda forma de discurso metafísico como lenguaje carente de sentido. La ciencia constituye el único discurso legítimo $(-)$, de modo que la filosofía $(-)$ se reduce al análisis lógico-lingüístico de las proposiciones científicas. París advierte en la opción neopositivista la presencia de una criptometafísica—es decir una metafísica irreflexiva—de corte empirista, que reduce la teoría científica a un sistema de enunciados legaliformes limitados a la descripción de las constantes fenoménicas (París 1951-52, 46; París 1952a, 41-42).

Por último, el realismo escolástico (París 1952a, 60-73), se asienta en una sólida metafísica realista, cuyo deslinde constituye la principal tarea del saber filosófico $(+)$. Se presupone asimismo que sobre ese discurso metafísico, en su vertiente filosóficonatural, se fundan los principios de la ciencia $(+)$. Sin embargo, salvo excepciones como el Padre Selvaggi-muy próximo a Carlos París-, los filósofos escolásticos han sido escasamente proclives a derivar, a partir del realismo aristotélico-tomista, una epistemología que diera cumplida cuenta de los desarrollos de la ciencia moderna ( $\mathrm{Pa}$ rís 1949, 311-12), especialmente en sus logros más recientes, precisamente los que parecen impugnar las intuiciones del sentido común, punto de partida habitual en esta tradición.

A partir de aquí, la filosofía de la naturaleza es presentada como la disciplina que permite articular las reflexiones epistemológicas sobre la ciencia y la especulación metafísica (París 1954b, 136). Aquí se recogen también dos elementos teóricos recibidos de la herencia orteguiano-zubiriana. En primer lugar, una noción de ciencia que entronca con la episteme griega y que apunta a explicar cómo son las cosas (realismo) y no meramente cómo aparecen (positivismo) (Moreno Pestaña 2008, 38-41). En segundo lugar se insiste en el monopolio filosófico de la reflexividad: la ciencia no es consciente del impensado teórico que funda sus operaciones-aquí se advierte la dualidad orteguiana de "ideas" y "creencias"-, lo que ofrece a la filosofía un quehacer no sólo legítimo sino superior, pues una ciencia que ignora sus fundamentos queda rebajada a mero saber técnico (París 1949, 299-301; París 1952a, 46).

Sobre este trasfondo de estrategias argumentativas se produce la recepción de Bachelard en la obra de Carlos París. Éste no alude a Bachelard considerándolo como un autor aislado, sino encuadrado en una "concepción" o "movimiento" más amplio, encarnado en la revista Dialectica (fundada en 1947) editada en Zurich, y cuyos representantes principales serían el propio Bachelard, el filósofo suizo Ferdinand Gonseth y 
el matrimonio Destouches (Jean-Louis y Paulette) (París 1952a, 279). ${ }^{19}$ Las raíces de este movimiento las localiza París en las primeras décadas del siglo XX, en las contribuciones de Léon Brunchsvicg y de Émile Meyerson (París 1952a, 178; París 1954b, 28). ${ }^{20}$

Por otro lado, Carlos París no mantuvo con Bachelard (ni con el matrimonio Destouches) una relación meramente libresca. En una estancia en la capital francesa que debió de realizar a comienzos de la década de 1950, visitó al filósofo en su casa, intercambiando puntos de vista parcialmente coincidentes-especialmente en el rechazo de ambos al empirismo neopositivista (París 2006, 114-115). A estas alturas y aunque aún no era muy conocida en España, la obra de Bachelard ya iba alcanzando cierta difusión. Aparte del caso de José Pemartín y de algunos comentarios de Gustavo Bueno coetáneos de la visita de París al filósofo, hay que referirse al trabajo de Díez Blanco (Díez Blanco 1951, 63-64), ${ }^{21}$ donde se hace un amplio uso de la Philosophie du Non (editada originalmente en 1940). ${ }^{22}$ Esta obra, además de Le Nouvel esprit scientifique (1934), son las más frecuentadas por Carlos París. ${ }^{23}$

La referencia a la epistemología de Bachelard le permite a París, en primer lugar, tomar distancia del apriorismo fijista de matriz kantiana (París 1952a, 143-144; París 1952d, 264; París 1954b, 44-45). La ciencia forma parte de un proceso de continua revisión que caracteriza al conocimiento en su conjunto; las estructuras conceptuales de la ciencia (por ejemplo la diferencia entre juicios analíticos y sintéticos) no son eternas sino móviles, poseen un característico "dinamismo" dialéctico (París 1953b, 368; París

${ }^{19}$ Ciertamente Bachelard—que se encontró por primera vez con Gonseth en París, en 1937—era amigo del filósofo suizo y antes de conocerlo ya citaba su obra Les fondements des mathématiques. También es cierto que ambos, junto a Paul Bernays (brazo derecho de Hilbert), fundaron en 1947 la revista Dialectica (Émery 2000, 177-80) Pero de ahí a considerar a Bachelard como miembro de una supuesta escuela, con la que sólo entró en contacto tardíamente, media un abismo y obedece al imperativo de descontextualizar la aportación bachelardiana para recontextualizarla en el universo filosófico español. En la biografía autorizada de Bachelard (Parinaud 1996), ni siquiera se menciona a Gonseth. La comprensión adecuada de la contribución bachelardiana pasa por emplazarla en el campo de la filosofía francesa y de sus debates epistemológicos en las cuatro primeras décadas del siglo XX (Castelao 1997; Castelli 1998, 244-54; Brenner 2003, 99-108; y Chimisso 2008, 139-51).

${ }^{20}$ De hecho, el realismo de Meyerson tuvo inicialmente una incidencia mayor en la obra de Carlos París que la obra del propio Bachelard. A partir de (París 1951), se toma cierta distancia de la epistemología meyersoniana, debido a la dificultad para conciliar el realismo de ésta con la física cuántica y por lo que considera una postrera deriva escéptica de Meyerson (París 1951, 216-218). París minimiza las diferencias entre los planteamientos de Meyerson y de Bachelard, obviando las rotundas críticas de éste al realismo meyersoniano y a su continuismo entre el sentido común y la ciencia, guiados por la misma lógica de reducción de lo diverso a identidad (Bachelard 1978, 82-85).

${ }^{21}$ En (Anon. 1950, 161-166) se da noticia del Congreso Internacional de Filosofía de las Ciencias celebrado en París bajo la presidencia de Émille Borel y Gaston Bachelard, al que asistieron, en representación de España, el profesor Sixto Ríos y el Padre Echarri.

22 A esto hay que añadir la estancia durante tres años (1945-1948) de Roberto Saumells estudiando filosofía y matemáticas en la Sorbona, junto a Bachelard, Poirier, Jean Wahl y Gouhier, a la que nos referiremos posteriormente.

${ }^{23}$ En un segundo plano se alude al Essai sur la connaissance approchée (1927), La formation de l'esprit scientifique (1937) y Le rationalisme appliqué (1949). 
1954b) marcado por el error (“obstáculo epistemológico") (París 1954b, 38) y por su rectificación (París 1952a, 178; París 1953b, 375).

Frente al convencionalismo al estilo de Duhem, Bachelard enseña que la filosofía no puede elaborarse sin tener en cuenta los logros efectivos de la actividad científica. La filosofía de la naturaleza debe atender a los análisis de una epistemología abierta al decurso de los conceptos científicos. Las teorías fabricadas por los científicos apuntan a capturar la realidad externa, tienen un alcance ontológico (París 1952a, 277). El simbolismo matemático de la física contemporánea no es sólo un lenguaje descriptivo que "salva los fenómenos" sino que tiene una condición constitutiva de la realidad (París 1952a, 200-202).

Frente al neopositivismo, cuya filosofía de la ciencia remite al ideal de un lenguaje lógicamente perfecto, la epistemología bachelardiana toma como piedra de toque el decurso histórico de la ciencia (París 1957a, 405). En esta opción por la historia antes que por los análisis lógico-lingüísticos, París se muestra formando parte de una dinastía claramente francesa (París 1953b, 370). No se asimilan las teorías científicas como algo ya hecho (Faktum) sino como un proceso (in fieri) (París 1957c, 423-24), de modo que la referencia a la experiencia fenoménica inmediata-último fundamento de las teorías en el positivismo lógico-constituye sólo un momento provisional, negado y a la vez superado ("dialéctica") por el momento de conceptualización y axiomatización (París 1952a, 285-94).

Por último, frente a una herencia escolástica remisa a tener en cuenta, para su filosofía de la naturaleza, los resultados de la actividad científica (París 1952c, 49), se retoma el consejo bachelardiano de instruir a la filosofía en las lecciones epistemológicas que imparte la ciencia en marcha, aunque preservando, a diferencia del pensador francés, un margen de autarquía y un papel fundador al discurso filosófico (París 1952a, 321). En la estela de Pemartín, pero de un modo más sofisticado, París concilia el planteamiento de Bachelard y en general del "movimiento dialéctico", con el realismo aristotélico-tomista. Así por ejemplo, equipara el proceso de rectificación que conduce de la experiencia inmediata al concepto, con la teoría aristotélica de los "grados de abstracción" (París 1952d, 265), calificando este realismo como "realismo abstraccionista" (París 1954a, 388; París 1955a, 198-9; París 1957a, 406-7).

Esta adaptación de la "filosofía del no" al aristotelismo escolástico le obliga también a reformular la noción de sustancia, que en su formulación clásica-identificada con el ente singular a partir del hilemorfismo-, choca de lleno con los hallazgos de la física contemporánea, especialmente con la microfísica de los quanta (París 1951-52, 43; París 1957c, 425). Por eso París recurre a la redefinición del concepto de sustancia en la obra de Amor Ruibal, donde aquella es tematizada, no desde el modelo del ente individual, sino como totalidad de relaciones (París 1955b, 77, 87, 91-92; París 1958, 206).

La acomodación de la filosofía del no bachelardiana al realismo transmitido por la filosofía perenne no se efectúa sin dificultades. Aquí Carlos París opta por separarse del "movimiento dialéctico" y pone de relieve lo que estima como deficiencias y carencias de esta concepción (París 1954b, 38-39). 
En primer lugar, Bachelard y sus adláteres operan con una insuficiente dialectización. Se quedan en el plano epistemológico, mostrando las complejas relaciones entre teoría y experiencia, pero no franquean el umbral hacia la ontología y mucho menos hacia la metafísica. Frente a la dialéctica restringida defendida por el grupo francófono, París promueve una dialéctica generalizada (París 1954b, 28-35). ${ }^{24}$ Este movimiento traduce el afán de trascendencia (París 1951-52, 40-46; París 1953b, 362) inherente al espíritu humano, que se desplaza irresistiblemente desde lo empírico hacia lo ultraempírico o de lo contingente hacia lo necesario (París 1956, 190). Así, los conceptos bachelardianos de "error", "rectificación" y "aproximación" se revelan como señas de una finitud humana situada en una esfera ontológica, una aspiración que iría más allá del ser material estudiado por la ciencia, hacia lo absoluto, hacia el Acto Puro (París 1954b, 46-48).

En segundo lugar, esta despreocupación ontológica y metafísica propia de la escuela dialéctica, hace que sus análisis no vayan más allá del plano del ente materialasunto de la ciencia-sin trascenderlo. De ahí el peligro de recaer en el materialismo, que es la filosofía espontánea del científico natural (París 1953a, 253; París 1954b, 36; París 1956, 181). ${ }^{25}$ Por otro lado, al carecer de una filosofía natural (París 1952a, 53), al no fundar la epistemología sobre bases ontológicas y metafísicas (París 1954a, 389), sino a partir de algo tan provisional como la historia de la ciencia, Bachelard y la concepción dialéctica eliminan todo fondo inmutable en los principios mismos de la ciencia (identidad, causalidad, no contradicción, etc), abriendo la senda del escepticismo (París 1954a, 389; París 1954b, 46). Se reitera aquí, como sucedía en Pemartín, la exigencia, la llamada al orden-propia de un insider académico y de un seuísta convencido, como era entonces París-para respetar la debida jerarquía entre las disciplinas: la filosofía se emplaza en un nivel más fundamental y superior que las ciencias (París 1949, 301); no hay epistemología sin cimientos ontológicos y metafísicos.

Por último, Bachelard exagera la discontinuidad existente entre la ciencia y el sentido común (París 1952a, 327-30)—con el énfasis en las "rupturas"—y olvida el continuismo-al menos en el nivel de las regularidades empíricas descubiertas (París 195152, 47; París 1952b, 176)—en el terreno de la historia de la ciencia, poniendo así en riesgo la unidad del conocer humano.

${ }^{24}$ Curiosamente, podría decirse que Carlos París parece caer precisamente en un obstáculo epistemológico analizado y exorcizado por Bachelard: el obstáculo del "conocimiento general", donde aquello que se constata en un área delimitada del conocimiento, se generaliza de modo salvaje e indiscriminado, ontologizándolo (Bachelard 1974, 66-98).

${ }^{25}$ Curiosamente, a pesar de citar El Racionalismo aplicado, donde Bachelard ya se había referido al racionalismo aplicado como un "materialismo instruido" (por la dialéctica de la razón y de la técnica en la ciencia actual) (Bachelard 1978, 11), París jamás alude a la epistemología bachelardiana calificándola de materialista. Su lectura selectiva no tiene en cuenta los conceptos que irían en esa dirección (por ejemplo la distinción entre "fenomenología" y "fenomenotecnia") ni cita nunca Le matérialisme rationnel (1953), donde el filósofo francés desarrolla más explícitamente ese planteamiento. Estos mismos silencios se constatarán en el caso de Roberto Saumells. Habrá que esperar a la década de los 70 , con la recepción de la epistemología histórica francesa a través del althusserianismo, para encontrar en España una lectura materialista de Bachelard. 


\section{Bachelard y el realismo de la forma: Roberto Saumells}

Junto a Carlos París, el pensador español que más contribuyó a la recepción de la epistemología bachelardiana fue el catalán Roberto Saumells (nacido en 1916). Ambos pertenecían a escuelas de pensamiento rivales, que llegaron a convertirse en antagónicas. Como ha señalado Moreno Pestaña (2010), la pertenencia a una "escuela de pensamiento" puede implicar tres características que no siempre se dan conjuntamente. Tiene que ver en primer lugar con la entrada en una red institucional, esto es, la dependencia respecto a personas que entronizan al sujeto en una carrera permitiéndole la acumulación de capital académico en un plazo más o menos largo. Como se ha visto, Carlos París fue tutelado en su tesis doctoral por Yela Utrilla, un falangista ortodoxo; hizo su aprendizaje intelectual en las revistas de los círculos intelectuales seuístas y se mantuvo cercano del grupo cultural ligado a finales de los años cuarenta con el Instituto de Cultura Hispánica. Sin embargo su temprano encumbramiento a la cátedra (de Fundamentos de Filosofía en Santiago de Compostela) tuvo lugar gracias a avatares coyunturales relacionados con las pugnas del poder universitario, no en virtud del respaldo dado por este sector (París 2006, 49-51). ${ }^{26}$

En segundo lugar, una escuela de este tipo remite a un grupo de acción intelectual relativamente estable que se convierte en fuente de "energía emocional" renovable. En el caso de Carlos París a la altura de los primeros años cincuenta, ese grupo estaba emplazado en la sección de Filosofía e Historia de las Ciencias del Instituto Luis Vives del CSIC, dirigida por Rey Pastor. La trayectoria intelectual de Roberto Saumells lo emplazaba en una escuela intelectual rival que llegó a convertirse en antagónica. ${ }^{27} \mathrm{De}$ origen social más modesto y provinciano que París—nació en Gironella, cursó el bachillerato en Tarragona y sus padres eran maestros nacionales, Saumells, que había hecho la Guerra en el bando republicano, encarnó el prototipo del "buen alumno"28 (Premio Extraordinario en Bachillerato), consiguiendo de este modo, después de cursar la carrera de Filosofía en Barcelona, una beca del Instituto Francés para ampliar estudios. En París residió durante tres años (1945-1948), frecuentó la Sorbona y siguió las clases, entre otros, de Bachelard. Cuando los recursos derivados de la beca estaban cerca de agotarse, recibió una subvención de la dirección de Relaciones Culturales gracias a su director de tesis, Rafael Calvo Serer. Este estaba empeñado en la tarea de confeccionar una red de contactos internacionales con intelectuales europeos, contri-

${ }^{26}$ Junto al voto de Jesús Arellano y del presidente del tribunal, París recibió el del falangista y arabista Cruz Hernández, que años antes se había ofrecido servilmente como aliado de Calvo Serer (Díaz Hernández 2008, 344-345). En cualquier caso, la anécdota revela lo que antes se comentó: a la altura de 1951, la rivalidad entre el grupo de Arbor (Calvo Serer) con los grupos del Instituto de Cultura Hispánica (acenepistas de Ruiz-Giménez) y del Instituto de Estudios Políticos (falangistas zubirianos próximos a Javier Conde), no excluía la estrecha colaboración.

${ }^{27}$ Sobre la trayectoria de Roberto Saumells se han consultado los trabajos de (Cimadevilla 1956; González Quirós 1997; Díaz Hernández 2008; y López Quintás 1970, 657-670). Agradezco al profesor González Quirós por haberme facilitado un ejemplar de la entrevista de 1997.

${ }^{28}$ Sobre las características de este "idealtipo" del "buen alumno", contrapuestas a las del "alumno brillante”, (Vázquez García 2009, 101-102 y 266). 
buyendo a mejorar de este modo-en el contexto del aislacionismo posterior a 1945y en el terreno cultural, la imagen exterior del régimen (Díaz Hernández 2008, 75). Saumells se convirtió desde entonces en hombre de confianza de su mentor. A su regreso a España y bajo los auspicios de Calvo Serer, recibió diversos cargos en distintas unidades del CSIC y más tarde se integró en el Departamento de Filosofía de la Cultura (CSIC), dirigido también por su maestro, formando equipo junto a Millán Puelles, Osvaldo Market y Miguel Siguán. Por último, en 1950 ingresó en la Universidad de Madrid como encargado de curso impartiendo la asignatura de Cosmología, hasta entonces explicada por Carlos París. En esa misma época ingresó como numerario en el Opus Dei.

De este modo, a finales de los cuarenta y comienzos de la década de los años cincuenta, Carlos París y Roberto Saumells figuraban respectivamente en grupos de acción intelectual rivales dentro del Instituto Luis Vives del CSIC. Por una parte el departamento de Filosofía e Historia de las Ciencias; por otra el departamento de Filosofía de la Cultura (aliado al de Culturas Modernas); de un lado THEORIA, del otro $A r$ bor, en un grupo la preeminencia de Calvo Serer y los contactos con personajes como Pérez Embid (Ateneo, Dirección General de Información), Antonio Fontán (Actualidad Española) o Fernández de la Mora (Ateneo); en el otro, el poder de Ruiz-Giménez (embajador en la Santa Sede), Sánchez Bella (Instituto de Cultura Hispánica), Laín Entralgo (Escorial, Editora Nacional) y Javier Conde (Instituto de Estudios Políticos). El ascenso de Ruiz-Giménez al Ministerio de Educación Nacional hizo que la balanza se inclinara del lado de los aliados de Carlos París. ${ }^{29}$ En las vísperas de esa situación tuvo lugar la fracasada defensa de la tesis doctoral de Saumells, que se vio obligado a dejar su docencia de Cosmología (Díaz Hernández 2008, 266 y París 2006, 124-25). Posteriormente y en medio del antagonismo cada vez más abierto entre Calvo Serer y RuizGiménez se produjo la caída en desgracia del primero y la disolución del grupo Arbor. Saumells, después de conseguir por fin el título de doctor (con una nueva tesis), obtuvo en 1953 una beca para realizar una estancia de varios meses en París; posteriormente y sin dejar su vinculación con el CSIC, se trasladó a la Universidad de Costa Rica, donde llegó a desempeñar docencia como profesor extraordinario.

Una escuela intelectual puede implicar por tanto la existencia de una red institucional y de un grupo intelectual de apoyo mutuo. Ambas características se verifican en los casos de estos dos importadores de Bachelard que fueron París y Saumells. Sin embargo en ninguno de los dos casos puede reconocerse la presencia de una tercera característica señalada (Moreno Pestaña 2010): la existencia de una problemática teórica compartida, de un dispositivo conceptual común. Sin duda existían afinidades ideológicas e incluso filosóficas que distinguían a los hombres de Calvo Serer de los hombres de Laín, en ningún caso codificables bajo la oposición simplista entre conservadurismo y liberalismo. Todo esto es muy poco para hablar de doctrinas filosóficas en liza. La recepción de Bachelard, como ahora se probará, muestra esta circunstancia.

${ }^{29}$ Años después, en el contexto de la pujante presencia de Ministros opusdeístas en el Gobierno de Franco, el signo se invertiría y París habría de perder la cátedra de Filosofía de la Naturaleza en la Universidad de Madrid, a favor de Saumells (París 2006, 125-26 y Mindán 2004, 166). 
Más allá de sus tremendos antagonismos institucionales y personales, las lecturas de Bachelard propuestas por París y por Saumells llaman la atención por su similitud. Con estilos y matices diferentes, ambos tratan de conciliar la epistemología bachelardiana y su atención a la actualidad científica con la tradición escolástica del realismo.

El punto de partida donde se emplaza Saumells, y esto desde sus primeras publicaciones, lo constituye el conflicto entre razón y representación que la ciencia contemporánea ha llevado al extremo. Esta se apoya en una racionalidad puramente discursiva, de tipo axiomático, que implica romper con toda referencia a lo inmediatamente representable por la intuición. Esta verdadera iconoclastia de la física matemática actual habría sido diagnosticada con tino en la obra de Bachelard. Al mismo tiempo, y aquí la referencia a Meyerson es inevitable, Saumells considera que la tendencia del espíritu humano a traducir los conceptos abstractos en la forma de representaciones, es insoslayable. Llegará a sostener que "el realismo filosófico preconiza la imagen y el racionalismo la posterga" (Saumells 1958, 142-43).

¿Cómo compatibilizar entonces el realismo con el hiperbólico formalismo racionalista de la ciencia en curso?; ¿cómo preservar la noción de "sustancia" si el "sustancialismo", como ha denunciado el propio Bachelard, constituye, precisamente por su engañosa claridad intuitiva, uno de los principales obstáculos que impiden la constitución de los conceptos científicos?

La estrategia argumentativa de Saumells consistirá en recurrir a la "dialectización" bachelardiana, con objeto de problematizar las antítesis epistemológicas recibidas: empirismo/ formalismo, intuicionismo/ logicismo o convencionalismo/ realismo. De este modo, las proposiciones y tesis contrarias son presentadas como momentos provisionales de un movimiento dialéctico que caracterizaría al proceso cognoscitivo.

Ahora bien, a diferencia de Carlos París, este recurso a la dialectización no consiste en presentar vastos estados de la cuestión donde se discuten, en términos generales, las distintas posiciones rivales con objeto de elaborar una propuesta propia. Saumells procede de un modo más parecido al del propio Bachelard; selecciona un dominio conceptual restringido y lo examina en sus condiciones históricas de aparición. Las propias posiciones se revelan de un modo muy elusivo, a través de estos análisis histórico-epistemológicos concretos. Como se ha sugerido, esta tendencia a la delimitación estricta de los problemas tiene que ver con la fobia al ensayismo ("hablar de todo lo divino y lo humano de una manera blanda y nebulosa" (Cimadevilla 1956) y con una decidida voluntad ascética de rigor y tecnicismo, algo que puede encontrarse en otros compañeros del mismo círculo intelectual de Saumells (Vázquez García 2009, 87-88).

El teorema de Desargues, el postulado euclídeo de las paralelas, la geometría proyectiva de Von Staudt, la teoría maxwelliana del campo electromagnético, la refutación del éter en el experimento de Michelson, el concepto de "caída de los graves" en la física galileana, este es el tipo de problemas cuyo detenido análisis y reflexión, ocupan la obra epistemológica de Saumells entre 1949 y 1958. En el examen de estas cuestiones más que glosar a Bachelard, lo que se hace es aplicar su estilo de exploración, incluso para poner en tela de juicio al propio Bachelard-utilizado para cuestionar el empirismo neopositivista pero acusado por Saumells (Saumells 1949, 465) de caer en un formalismo a ultranza. Aparte de La philosophie du non o de Le nowvel esprit scientifique, se 
alude a textos bachelardianos mucho menos frecuentados por Carlos París, como La formation de l'esprit scientifique (1937); La valeur inductive de la relativité (1929), L'intuition de l'instant (1932) o La dialectique de la durée (1936).

En su tesis doctoral, Saumells puso a prueba este proceder por "dialectización”, en relación con la noción de "espacio". Partía del estudio de uno de los teoremas básicos de la Geometría Proyectiva: el teorema de Desargues. Su demostración mediante razonamiento abstracto, puramente deductivo, no excluye sin embargo la posibilidad de construir una representación gráfica del mismo. Ahora bien, esa representación sólo es posible en la medida en que se trascienden las propiedades puramente intuitivas del plano. Se trataría de una representación no figurativa, no captable por la intuición inmediata sino obtenida precisamente por la "desfiguración" del espacio dado en la intuición sensible. De este modo, el razonamiento demostrativo no se funda en las propiedades intuitivas del plano; es autónomo respecto a la representación pero no es imposible representarlo. Saumells sugiere que esto es posible por la existencia de un isomorfismo entre las condiciones de demostración y las condiciones de representación. El espacio de la intuición contiene la posibilidad misma de ser trascendido, negado en un concepto cuya pura forma es susceptible de ser representada. Lo que se postula, por tanto, es un realismo contrario al del "sentido común", que identifica imagen y cosa (Saumells 1958, 196), un realismo que apela a la posibilidad de representar los conceptos a partir de las condiciones formales puestas por el propio concepto y no de las condiciones dadas en la intuición; un realismo de la forma y no de la materia (Saumells 1954, 19; Saumells 1958, 150), resultado de una compleja elaboración intelectual y no mero trasunto de la "actitud natural" (Saumells 1958, 162).

En la Dialéctica del espacio, Saumells traslada su proceder dialectizador, de inspiración bachelardiana, al análisis del concepto, no ya de espacio geométrico, sino de espacio físico. A partir de aquí se refiere al problema del tiempo. Introduce entonces el juego de tesis y antítesis entre Bergson y Bachelard. Este legitima la referencia a la simultaneidad a través de su teoría del tiempo como instante, enfatizando frente a Bergson la discontinuidad temporal y su vínculo con una psicología de la atención contrapuesta a la psicología bergsoniana de la intuición (Saumells 1952, 189-200). De este modo se introduce en España, por primera vez, la tematización bachelardiana de la temporalidad.

Por último, en La ciencia y el ideal metódico (1958), Saumells entra a dirimir, con el mismo recurso dialectizador, la polémica que enfrenta a dos puntos de vista: el que defiende que una ciencia se especifica principalmente por su método y el que sostiene que el criterio especificador consiste en el objeto. El autor se decanta por la segunda opción, que es obviamente la que está emparentada con el realismo, pero para probar su propuesta lleva a cabo un arduo recorrido en el que retoma análisis de problemas concretos que en algunos casos aparecían en su tesis doctoral. Ese conjunto de estudios histórico-epistemológicos le permiten diferenciar claramente el realismo de la forma de un realismo de "sentido común" que linda con el materialismo, al que tilda de "degradación misma de la filosofía" (Saumells 1958, 189-90).

Como en el caso de París, la instrumentalización de la obra de Bachelard por parte de Saumells no está exenta de críticas y de silencios selectivos. Sostener una interpre- 
tación realista y dialéctica de los conceptos científicos implica proporcionar una solución "inconmovible" acerca de los fundamentos metafísicos del pensamiento científico. Aquí aparece de nuevo el esquema jerárquico: para Saumells y frente a Bachelard, no es la ciencia la que instruye a la filosofía sino la filosofía la que justifica a la ciencia. La epistemología bachelardiana recoge sus valores a partir de la ciencia en curso y desde ellos elabora sus reconstrucciones racionales de la historia del conocimiento objetivo. Saumells considera que esta actitud conduce a un intolerable relativismo que remite a una petición de principio (Saumells 1952, 121, 125). Los fundamentos que explican la evolución de la ciencia, ¿cómo van a crearse y recrearse en esa misma evolución?

Por otro lado y como ha podido comprobarse, Saumells rechaza todo lo que pueda acercarse a un planteamiento "materialista" en epistemología; su realismo de la forma implica el "acto" y la "construcción"- frente al realismo de "lo dado"- pero apela a un mundo por contemplar, de intensas resonancias platónicas. El materialismo queda relegado ascéticamente al ámbito del conocimiento "en su forma inferior" (Saumells, 1958, 189-190), esto es, el conocimiento sensible en su modalidad más grosera: el tacto. Por esta razón, todas las referencias bachelardianas que presentan su epistemología como un materialismo ("técnico", "instruido", "racional") o que aluden a la diferencia entre "fenomenología" y "fenomenotecnia", 30 están ausentes en los escritos de Saumells.

\section{Conclusión}

El examen de la primera recepción española de la epistemología bachelardiana, entre los años cuarenta y cincuenta, permite advertir la importancia que tenía la tradición francesa en la filosofía de la ciencia española, y en particular el protagonismo que en aquella desempeñaba la reflexión sobre casos históricos. Al mismo tiempo se ha comprobado que algunos autores, gracias a contar con un destacado capital filosófico y científico como fueron los casos de Carlos París y Roberto Saumells, podían tomar cierta distancia respecto al espeso magma ideológico de la época, a la hora de adentrarse en cuestiones de orden epistemológico.

Comparando las tres principales estrategias de lectura de Bachelard que se han expuesto y que corresponden a las trayectorias respectivas de José Pemartín, Carlos París y Roberto Saumells, salta a la vista una diferencia importante en el grado de eufemización alcanzado por cada uno de ellos. En el primer caso el grado de violencia ejercido en relación con los textos bachelardianos es evidente; se trata de utilizar las críticas del cartesianismo al servicio de una ideología nacionalcatólica apenas disimulada. En el segundo caso, el respeto al texto y la autonomía de lo filosófico respecto a lo extrafilosófico son mucho más palpables. Pero Carlos París, en vez de practicar la epistemología bachelardiana en relación con el estudio de casos concretos en historia de la cien-

\footnotetext{
${ }^{30} \mathrm{~A}$ la absoluta centralidad del concepto de "fenomenotecnia" en la epistemología de Bachelard se ha referido recientemente Roberto Torretti. Esta noción implica poner en tela de juicio la tradicional escisión positivista entre la ciencia y sus aplicaciones tecnológicas (Torretti 2011: 99) y lleva a concebir la ciencia como una empresa social productora de fenómenos (Torretti 2011: 103).
} 
cia, optaba por usar sus tesis (enmarcadas en las referencias genéricas a una "escuela dialéctica") dentro de vastos estados de la cuestión. Se trataba de utilizar a Bachelard para hacer posible el aggiornamiento de una metafísica realista, de filiación tomistamatizada por las referencias a Amor Ruibal-conciliando así la doctrina de la Iglesia católica con la modernidad científica. En el caso de Saumells, sin embargo, las referencias a la ideología - no disimuladas por Pemartín- o incluso al dogma religiosopresentes en París-desaparecen, insinuándose una preferencia por la asepsia y por el tecnicismo, muy presentes también en otros autores vinculados en la década de los 50 al grupo de Arbor, como fue el caso de Millán Puelles. La ideología de la neutralidad tecnocrática y del "crepúsculo de las ideologías" se hace palpable en esta estrategia de lectura. Por otro lado, Saumells no se limita a citar o a comentar los textos bachelardianos, sino que trata de practicar este estilo de epistemología a partir del estudio de casos concretos tomados de la historia de la física y de la geometría modernas. No obstante, a pesar de las reconstrucciones retrospectivas que tratan de maquillarla, la impronta de la escolástica tomista, que marcaba el orden del día de la filosofía universitaria en la España de la época, es evidente en el modo en que todos estos autores reciben la obra de Bachelard. ${ }^{31}$ Esto se hace manifiesto en la mutilación de toda referencia al "materialismo" (considerado por todos estos autores como una negación de la filosofía) cuando se menciona la obra bachelardiana. ${ }^{32} \mathrm{~A}$ partir de finales de los años sesenta y primeros setenta, cuando se vuelva a forjar en España una comunidad intelectual dedicada al cultivo de la filosofía de la ciencia, esta herencia francesa será relegada, optándose por buscar los modelos en el ámbito de la tradición analítica. Bachelard será redescubierto por una vía diferente; a partir de la polémica acogida española del marxismo de Althusser. En ese contexto, en cambio, la referencia al "materialismo" ocupará un lugar principal.

La importación de Bachelard y de la "escuela dialéctica" dotará de un perfil singular a las aportaciones de Carlos París en materia de filosofía de la naturaleza, y le ayudarán a labrarse una fulgurante carrera universitaria en el medio filosófico de la década de los cincuenta. Sin embargo el giro antropológico y filosófico-existencial que se produce en su pensamiento desde finales de esa década — constatable en Mundo técnico y existencia auténtica, editada en 1959-y que acompañó también a su viraje en el ámbito ideológico, trajo consigo el desplazamiento de la epistemología a un segundo plano de sus intereses. Este "cambio de marcha" no se produjo en el caso de Saumells, cuyo apego por la filosofía de la naturaleza, proseguido por su discípulo Cándido Cimadevilla, lo relegaría a un segundo plano de la escena filosófica española posterior, que tendería a considerar la mencionada disciplina como un residuo del pasado, en contraste con la pujanza de una filosofía de la ciencia de pedigree analítico.

${ }^{31}$ El primer artículo publicado en España y dedicado íntegramente a comentar la obra epistemológica de Bachelard, insistía en su "proximidad ideológica" (Cavero 1958, 278) con los planteamientos del realismo aristotélico-tomista; por otro lado, el énfasis bachelardiano en la importancia del "error" revelaría una actitud "humilde ante Dios", frente a la soberbia cientista de los diversos "positivismos" (Cavero 1958, 278).

32 Esta orientación materialista es palpable en Le rationalisme appliqué (1949) y en Le matérialisme rationnel (1953). 
Al mismo tiempo, en este trabajo se ha tratado de mostrar que, en un contexto filosófico tan castigado como el español de los años cuarenta y cincuenta, la pertenencia a escuelas filosóficas rivales no implicaba necesariamente grandes disparidades teóricas. Carlos París y Roberto Saumells, situados en redes institucionales y en grupos intelectuales diferentes y en un momento dado antagónicos, leían a Bachelard desde planteamientos bastante similares, a pesar de esas diferencias que se han indicado. Por esta razón, los estudios sobre el tráfico internacional de los bienes filosóficos resultan especialmente útiles: nos ilustran más sobre el funcionamiento de las culturas importadoras que sobre los propios objetos importados.

\section{REFERENCIAS}

Álvarez de Linera, Antonio.1953. Reseña de La doctrina epistemológica de Raymundo Pardo, por Sociedad Argentina de Filosofía, Revista de Filosofía 12 (44): 163

Anon. 1950. Congresos. Revista de Filosofía 9 (32): 161.

AAVV. 1953. XXXII Sesión Científica. Condicionamientos antropológicos de la ciencia y de la técnica modernas. Revista de Filosofia. 12 (44): 149-158.

Ayala, Jorge M. 2005. J. D. García Bacca. Biografía intelectual (1912-1938). Madrid: Ediciones Diálogo Filosófico.

Bachelard, Gaston. 1929. La valeur inductive de la relativité. Paris: Vrin.

- 1932. Le pluralisme cohérent de la chimie moderne. Paris: Vrin.

- 1934. Le nouvel esprit scientifique. Paris. PUF.

- 1936. La dialectique de la durée. Paris: Vrin.

—. 1937. La formation de l'esprit scientifique: contribution à une psychanalyse de la connaissance objective. Paris: Vrin. (La formación del espiritu cientifico. Buenos Aires: Siglo XXI, 1974)

—. 1940. La philosophie du non: essai d'une philosophie du nouvel esprit scientifique. Paris: PUF.

-. 1953. Le matérialisme rationnel. Paris: PUF.

—. 1949. Le rationalisme appliqué. Paris: PUF (El racionalismo aplicado. Barcelona: Paidós, 1978).

Balibar, Etienne. 1978. From Bachelard to Althusser. The concept of epistemological break. Economy and Society. 7 (3): 207-237.

Becker, Howard S. 2002. Les ficelles du métier. Paris: La Découverte.

Bourdieu, Pierre. 1991. La ontología politica de Martin Heidegger. Barcelona: Paidós.

-. 1997. Méditations pascaliennes. Paris: Seuil.

Brenner, Anastasios. 2003. Les origines françaises de la philosophie des sciences. Paris: PUF.

Bueno, Gustavo. 1955. Las estructuras metafinitas. Revista de Filosofía 14 (53/54): 223-291.

Castelao, Teressa. 1997. Gaston Bachelard et le milieu scientifique et intellectuel français. En Actualité et posterités de Gaston Bachelard, ed. Pierre Nouvel, 101-116. Paris: PUF.

Castelli Gattinara, Enrico. 1998. Les inquietudes de la raison. Épistémologie et histoire en France dans l'entre-deuxguerres. Paris: Vrin, EHESS.

Cavero, Ignacio. 1958. El nuevo espíritu científico de Gaston Bachelard. Revista de Filosofía 17 (65/66): 267-282.

Chimisso, Cristina. 2008. Writing the history of the mind. Philosophy and Science in France, 1900 to 1960 s. Aldershot: Ashgate.

Cimadevilla, Cándido. 1956. Entrevista con Roberto Saumells. Punta Europa 2: 145-159. http://www.filosofia.org/hem/dep/pun/ta002145.htm (acceso el 28 de octubre de 2011)

Corominas, Jordi y Vicens, Joan Albert. 2005. Xavier Zubiri. La soledad sonora. Madrid: Taurus.

De Lorenzo, Javier. 2002. Miguel Sánchez-Mazas y el sueño de Leibniz. En Sánchez-Mazas, Miguel. Obras escogidas, vol. I, 11-23. San Sebastián: Universidad del País Vasco.

Díaz Hernández, Onésimo. 2008. Rafael Calvo Serer y el grupo Arbor, Valencia: Universidad de Valencia.

Díez Blanco, Alejandro. 1951. Nuevas Lógicas. Revista de Filosofía 10 (36): 43-77.

Émery, Eric. 2000. La notion de temps chez Bachelard et Gonseth, En Bachelard dans le monde, ed. Jean Gayon y Jean Jacques Wunenburger, 177-186. Paris: PUF. 
Ferraz, Antonio. 1997. La etapa epistemológica en el pensamiento de Carlos París. En Ciencia, técnica y cultura. Homenaje a la figura y la obra de Carlos París, 69-72. Madrid: UAM.

Fichant, Michel. 1973. L'épistémologie en France. Histoire de la philosophie, idées, doctrines, vol. 4, ed. François Chatêlet. París: Hachette.

—. y Michel Pécheux. 1969. Sur l'histoire des sciences. Paris: Maspero.

García Bacca, Juan David. 1982. Autobiografía intelectual. Anthropos 9: 4-10.

Glick, Thomas F. 1986. Einstein y los españoles. Ciencia y sociedad en la España de Entreguerras. Madrid: Alianza Universidad.

González Fernández, Antonio. 1994. Un solo mundo. La relevancia de Zubiri para la teoría social, tesis doctoral, Madrid: Universidad Pontificia Comillas.

González Quirós, José Luis. 1997. Entrevista a Roberto Saumells, Nueva Revista 51: 14-34.

Jiménez García, Antonio. 1982. El Instituto Luis Vives de Filosofía del CSIC. En Actas del III Seminario de Historia de la Filosofía Española, tomo 2, Ed. Antonio Heredia Soriano, 23-66. Salamanca: Universidad de Salamanca.

Juliá, Santos. 2004. Historia de las dos Españas. Madrid: Taurus.

Lecourt, Dominique. 1972. Pour une critique de l'épistémologie. Paris: Maspero.

López Quintás, Alfonso. 1970. Filosofía española contemporánea. Madrid: BAC.

Madrid, Carlos M. 2005. A vueltas con Ortega, la física y Einstein. Revista de Occidente 294: 5-20. http://www.revistasculturales.com/articulos/97/ (acceso el 28 de octubre de 2011).

Mannheim, Karl. 1993. El problema de las generaciones. REIS 62: 193-242.

Marsal, Juan Francisco. 1979. Pensar bajo el franquismo. Barcelona: Península.

Mindán Manero, Manuel. 2004. Mi vida vista desde los cien años. Zaragoza: Sdad. Cooperativa de Artes Gráficas.

Mínguez Pérez, Carlos. 1987. Física y filosofía. Anthropos 77: 56-57

- 1997. Ciencia y filosofía: dos polos de racionalidad. En Ciencia, técnica y cultura. Homenaje a la figura y la obra de Carlos París, 63-68. Madrid: UAM.

Morán, Gregorio. 1998. El maestro en el erial. Ortega y Gasset y la cultura del franquismo. Barcelona: Tusquets.

Moreno Pestaña, José Luis. 2008. Filosofía y sociología en Jesús Ibáñez: Madrid: Siglo XXI

—. 2010. Qu'est-ce qu'un héritage intellectuel ? A propos du corps et de la politique chez Merleau-Ponty et Foucault. http://hdl.handle.net/10498/14469 (acceso el 25 de octubre de 2011)

Ortega y Gasset, José. 1924. El sentido histórico de la teoría de Einstein. En Obras Completas, vol. 3, Madrid: Alianza Editorial, 1947: 231-242.

—. 1937. Bronca en la Física. En Obras Completas, vol. 5, Madrid: Alianza Editorial, 1983: 281-283.

Parinaud, André. 1996. Bachelard. Paris: Flammarion.

París, Carlos. 1949. La problematización del hecho científico en la conciencia moderna. En Ciencia, conocimiento, ser, 297-317. (Santiago: Universidad de Santiago, 1957).

- 1951. Émile Meyerson y la inteligibilidad de lo material. En Ciencia, conocimiento, ser, 211-248. (Santiago: Universidad de Santiago, 1957).

—. 1951-1952. La crítica neopositivista de la metafísica. Santiago de Compostela: Universidad de Santiago.

- 1952a. Física y filosofía. El problema de la relación entre ciencia física y filosofía de la naturaleza. Madrid: CSIC.

- 1952b. Sobre la evidencia objetiva en ciencia y en filosofía. En Ciencia, conocimiento, ser, 165-177. (Santiago: Universidad de Santiago, 1957).

-. 1952c. Sentido y alcance de una posición realista en la actual filosofía de la ciencia. Theoria 2: 49-50.

—. 1952d. Experience et théorie en Physique. Dialectique 6 (3): 264-265.

-. 1953a. El sentido de la explicación física. En Ciencia, conocimiento, ser, 249-257. (Santiago: Universidad de Santiago, 1957).

-. 1953b. Antropología y epistemología. En Ciencia, conocimiento, ser, 353-376. (Santiago: Universidad de Santiago, 1957).

- 1954a. Planteamiento de una posición realista en la actual filosofía de la ciencia. En Ciencia, conocimiento, ser, 379-389. (Santiago: Universidad de Santiago, 1957).

—. 1954b. El dinamismo del conocimiento. Arbor 29: 28-49, 105-106.

—. 1955a. La naturaleza de la filosofía en relación a las ciencias. En Ciencia, conocimiento, ser, 195-203. (Santiago: Universidad de Santiago, 1957). 
—. 1955b. La filosofía de la naturaleza en Amor Ruibal. En Ciencia, conocimiento, ser, 65-92. (Santiago: Universidad de Santiago, 1957).

—. 1956. La recuperación de la metafísica en la problemática actual. En Ciencia, conocimiento, ser, 179-192. (Santiago: Universidad de Santiago, 1957).

—. 1957a. ¿Qué son las leyes físicas?. En Ciencia, conocimiento, ser, 395-409. (Santiago: Universidad de Santiago, 1957).

—. 1957b. Hipótesis y teoría en física. En Ciencia, conocimiento, ser, 411-425. (Santiago: Universidad de Santiago, 1957).

-. 1957c. El concepto de ciencia natural en Ortega. En Ciencia, conocimiento, ser, 37-63. (Santiago: Universidad de Santiago, 1957).

—. 1958. Las grandes líneas evolutivas de la Física y el concepto de sustancia. Revista de Filosofía, 17 65/66: 195-206.

—. 1959. Mundo técnico y existencia auténtica. Madrid: Guadarrama.

—. 2006. Memorias sobre medio siglo. Barcelona: Península.

Pemartín, José. 1941. Introducción a una filosofía de lo temporal. Doce lecciones sobre espacio-tiempo-causalidad. Madrid: Espasa Calpe.

-. 1944. 'Epígonos' de la era cartesiana. Revista de Filosofía 3 (10/11): 435-467.

-. 1946. Sobre el tiempo. Una nueva teoría de la relatividad. Revista de Filosofía 5 (58): 475-497.

-. 1952. Sobre recursos de 'inconstitucionalidad' en torno a problemas de enseñanza en los Estados Unidos. Arbor, 22 (79-80): 382-389.

Peña, Lorenzo. 1993. Conmemoración del cuadragésimo aniversario de la revista Theoria. Isegoría 8: 321 323.

Pinto, Louis. 2009a. La théorie souveraine. Les philosophes français et la sociologie an Xxe siècle. Paris: Cerf.

—. 2009b. Introduction a Le commerce des idées philosophiques, ed. Louis Pinto, 9-15. Paris: Éditions du Croquant.

Poincaré, Henry. 1944. Ciencia y método. Madrid: Espasa Calpe.

- .1946. El valor de la ciencia, Madrid: Espasa Calpe.

Quiroga Fernández de Soto, Alejandro. 2007. Los orígenes del nacionalcatolicismo. José Pemartin y la Dictadura de Primo de Rivera. Granada: Comares.

Rodríguez Puértolas, Julio. 2008. Historia de la literatura fascista española, 2 vols. Madrid: Akal.

Ronzón, Elena. 1983. La revista Theoria y los orígenes de la filosofía de la ciencia en España (I). El Basilisco 14: 9-40.

—. 1992. Algo más acerca de 'Theoria', e índices (1952-1955). Theoria 16-17-18 (t. A): 623-644.

Sánchez-Mazas, Miguel. 1952. Importancia de los estudios de filosofía de las ciencias y de filosofía científica. Revista de Filosofía 11 (40): 65-72.

- 1992. Tiempo de razón, tiempo de análisis, tiempo de crítica, tiempo de creación, tiempo de libertad. Theoria, 7, no $16-17-18$, tomo A: 1-7

—. 1996. 'Calculemos.' Matemáticas y libertad. En Calculemos. Matemáticas y libertad. Homenaje a Miguel Sánchez-Mazas, 13-31, ed. Javier Echeverría, Javier De Lorenzo y Luis Peña. Madrid: Trotta.

Sánchez Ron, José Manuel. 1999. Cincel, martillo y piedra. Historia de la ciencia en España (siglos XIX y XX). Madrid: Taurus.

Saumells, Roberto. 1949. Sobre la estructura interna del conocimiento científico. Arbor 13 (43/44): 462466.

- 1952. La dialéctica del espacio. Madrid: CSIC.

—. 1954. La caída de los graves en Galileo. Madrid: Ateneo.

-. 1958. La ciencia y el ideal metódico. Madrid: Rialp.

- 1961. Fundamentos de matemática y de física. Madrid: Rialp

Tiles, Mary. 1984. Bachelard: science and objectivity. Cambridge: Cambridge U.P.

Torretti, Roberto. 2011. Fenomenotecnia y conceptualización en la epistemología de Gaston Bachelard. Theoria 72: 97-114.

Vázquez García, Francisco. 2009. La filosofía española. Herederos y pretendientes. Una lectura sociológica (19631990). Madrid: Abada.

Worms, Frédéric. 2009. La philosophie en France an XXe siècle. Paris: Gallimard.

Yela Utrilla, Juan Francisco. 1942. Galileo el ortodoxo. Revista de Filosofia 1 (1): 99-125. 
Zamora Bonilla, Javier. 2002. Ortega y Gasset. Barcelona: Plaza y Janés.

Zubiri, Xavier. 1934. La nueva física. Un problema de filosofía. Cruz y Raya 10: 8-94.

—. 1941. Ciencia y realidad. Escorial 10: 177-210.

-. 1978. Naturaleza, historia, Dios. Madrid: Editora nacional.

Francisco Vázouez García es Catedrático de Filosofía por la Universidad de Cádiz. Ha realizado estancias como investigador becado en el Centre Michel Foucault (Paris) y en el Centre de Recherches Historiques de l'École des Hautes Études en Sciences Sociales (Paris). Especialista en filosofía contemporánea española y francesa y en historia cultural de la sexualidad. Sobre estos temas ha publicado una veintena de libros y numerosos artículos en revistas internacionales.

Dirección: Departamento de Historia, Geografía y Filosofía, Universidad de Cádiz, Avda. Gómez Ulla s/n 11003 Cádiz, España. E-Mail: francisco.vazquez@uca.es 